\title{
Study of Influential Parameters of the Caffeine Extraction from Spent Coffee Grounds: From Brewing Coffee Method to the Waste Treatment Conditions
}

\author{
Alexandre Vandeponseele, Micheline Draye (D, Christine Piot and Gregory Chatel *(D) \\ EDYTEM, University Savoie Mont Blanc, CNRS, F-73000 Chambéry, France; \\ Alexandre.vandeponseele@univ-smb.fr (A.V.); micheline.draye@univ-smb.fr (M.D.); \\ christine.piot@univ-smb.fr (C.P.) \\ * Correspondence: gregory.chatel@univ-smb.fr
}

check for updates

Citation: Vandeponseele, A.; Draye, M.; Piot, C.; Chatel, G. Study of Influential Parameters of the Caffeine Extraction from Spent Coffee Grounds: From Brewing Coffee Method to the Waste Treatment Conditions. Clean Technol. 2021, 3, 335-350. https://doi.org/10.3390/ cleantechnol3020019

Academic Editor: Patrick Cognet

Received: 31 January 2021

Accepted: 3 March 2021

Published: 2 April 2021

Publisher's Note: MDPI stays neutral with regard to jurisdictional claims in published maps and institutional affiliations.

Copyright: (c) 2021 by the authors. Licensee MDPI, Basel, Switzerland. This article is an open access article distributed under the terms and conditions of the Creative Commons Attribution (CC BY) license (https:// creativecommons.org/licenses/by/ $4.0 /)$.

Abstract: This article aims to study the interest of spent coffee grounds (SCG) valorization through caffeine recovery. In an original way, this study takes into account all the parameters such as (i) the brewing coffee methods (household, coffee shops, etc.); (ii) the storage conditions, in particular the drying step; (iii) the solid/liquid extraction parameters such as the nature of solvent, the temperature, the extraction time and the solid/liquid ratio; and (iv) the liquid/liquid purification parameters such as the nature, the volume and the $\mathrm{pH}$ of extraction medium. Results have shown that spent coffee grounds from coffee-shops obtained by percolation contain a higher amount of caffeine than spent coffee grounds from households obtained from spent pods or filters. A drying treatment is not required when extraction is performed under one week after the spent coffee grounds collection with $96.4 \%$ of not degraded caffeine. Solid/liquid extraction performed with $25 \mathrm{~mL} \cdot \mathrm{g}^{-1}$ SCG of hydroalcoholic solvent (water/EtOH, v/v 60/40) at $60{ }^{\circ} \mathrm{C}$ during $15 \mathrm{~min}$ have given a caffeine yield up to $4.67 \mathrm{mg} \cdot \mathrm{g}^{-1}$ SCG. When using ethyl acetate, $93.4 \%$ of the caffeine has been selectively recovered by liquid/liquid extraction. Finally, the extraction of caffeine for the valorization of spent coffee grounds is a promising and easy way, which fits with an already important and well established market.

Keywords: spent coffee grounds; biomass valorization; caffeine; storage conditions; extraction parameters; purification

\section{Introduction}

Coffee is one of the most being traded commodity with an annual world production over 10 million tons in 2019 [1]. The path to produce a coffee beverage is long and leads to the generation of several by-products such as coffee husk, pulp, silverskin and spent coffee grounds (SCG). Coffee grounds represent the most valuable and available coffee by-product produced by soluble coffees industries, domestic houses, restaurants and coffee shops. Besides, it has been calculated that $650 \mathrm{~kg}$ of spent coffee grounds are generated from one ton of green coffee beans turned into coffee beverage [2].

Spent coffee grounds has been studied for high value applications such as production of biodiesel [3,4], bioethanol [5,6], biopolymer such as polyhydroxyalkanoate (PHA) [7,8], adsorbent for air depollution [9] or water depollution [10], and extracts of bioactive molecules such as polyphenols and caffeine [11-21]. Indeed, 1,3,7-trimethyl-1H-purine-2,6(3H,7H)dione, also called 1,3,7-trimethylxanthine or caffeine for coffee, theine for tea or guaranine for guarana, is the most widely used psychotropic substance all over the world (Figure 1) [22].

Caffeine can be incorporated in daily life products such as sodas and energy drinks [23], painkillers [24] or slimming creams [25]. Nowadays, coffee decaffeination is the most important known process to recover caffeine $[26,27]$. Extracted caffeine is the same as synthetic 
caffeine, expect that its economic value is higher due to its naturalness. However, caffeine from spent coffee grounds is rarely purified from raw extracts of bioactive molecules [18].<smiles>Cn1c(=O)c2c(ncn2C)n(C)c1=O</smiles>

Figure 1. The chemical structure of 1,3,7-trimethylxanthine (caffeine).

Hence, the aim of this work is to propose a full investigation of parameters of caffeine production from spent coffee grounds such as: (i) the brewing method in relation with the origin of spent coffee grounds (household, restaurants/coffee shops), (ii) the storage conditions with the influence of a drying step, (iii) the first step of solid/liquid extraction to recover caffeine from spent coffee grounds (nature of the solvent, extraction temperature and time, solid/liquid ratio) and (iv) the second step of liquid/liquid extraction to selectively recover caffeine (nature and volume of the solvent, $\mathrm{pH}$ ).

\section{Materials and Methods}

\subsection{Chemicals and Reagents}

Pure standard of caffeine, ethanol (96\% purity, not denatured), acetic acid ( $99.5 \%$ purity) and dichloromethane were obtained from ACROS ORGANICS. Acetonitrile, ethyl acetate, $n$-heptane and sodium hydroxide were supplied by Fisher Chemical. Chlorhydric acid $(37 \% \mathrm{w})$ was obtained from Roth. All solvents and reagents were of analytical grade and used as received.

\subsection{Plant Material}

Spent coffee grounds and roasted coffee beans used in this study have been obtained from a local bakery (R1) and from two restaurants (R2, R3). The bakery and restaurants prepare coffee beverage using the brewing method called percolation using professional high-pressure coffeemakers. The roasted coffee beans are from the same provider for each restaurant and are composed of a blend of $80 \%$ of Arabica and $20 \%$ of Robusta coffee. Individuals obtain spent coffee grounds through different ways: by percolation with household capsule coffeemakers (C1, C2), by percolation with mocha coffeemaker (M1) and by filtration with filter coffeemakers (F1). The amount of water required to brew the coffee was different for the household capsule coffeemakers $\mathrm{C} 1, \mathrm{C} 2\left(13 \mathrm{~mL} / \mathrm{g}_{\text {coffee }}\right)$, household filtration coffeemaker F1 (18 mL/g goffee), mocha coffeemaker M1 (unknown ratio) and restaurants R1, $\mathrm{R} 2$, R3 (unknown ratio). The residence time of water inside coffee were unknown in all cases.

\subsection{Storage of Spent Coffee Grounds (SCG)}

The spent coffee grounds from the bakery (R1) were used for the study of storage and solid/liquid extraction. A full week was required for the bakery to fill up a $25 \mathrm{~L}$ plastic bucket with spent coffee grounds that was then closed. The naturally wet (59.25\% water $w / w)$ spent coffee grounds were then stored at standard pressure and temperature in a close plastic bucket. Dry spent coffee grounds were obtained after $24 \mathrm{~h}$ in a $50{ }^{\circ} \mathrm{C}$ oven $(12.50 \%$ water $w / w)$.

\subsection{Solid/Liquid Extraction-General Protocol}

Extractions with dichloromethane, ethyl acetate or a solution at $0,20,40,60,80$ or $100 \%$ of EtOH in water $(v / v)$ were performed. A total of $1.43,2,3.33$ or $5 \mathrm{~g}$ of dry spent coffee grounds were mixed up with $50 \mathrm{~mL}$ of the studied solution in a round bottom flask magnetically stirred maintained at $20,40,60$ or $80^{\circ} \mathrm{C}$ in a water bath for 5,10 or $15 \mathrm{~min}$. 
The obtained extracts were filtered on a Buchner funnel equipped with a cellulose filter and rinsed with $10 \mathrm{~mL}$ of solvent. The resulting liquid extracts were then filtrated with a syringe filter $(0.22 \mu \mathrm{m}$, polyethersulfone (PES) membrane) before HPLC analysis.

\subsection{Liquid/Liquid Extraction-General Protocol}

The previous aqueous spent coffee grounds extracts were acidified with $0.5 \mathrm{~mL}$ of a $10 \% \mathrm{HCl}$ until $\mathrm{pH}=2$, basified by adding $1 \mathrm{~mL}$ of a $2 \mathrm{~N} \mathrm{NaOH}$ until $\mathrm{pH}=14$ or remained neutral at $\mathrm{pH}=7$. Liquid/liquid extractions were performed under magnetic stirring to treat the extract obtained in solid/liquid extraction with $60 \mathrm{~mL}(6 \times 10 \mathrm{~mL})$ or $180 \mathrm{~mL}$ $(6 \times 30 \mathrm{~mL})$ of dichloromethane, ethyl acetate, ethyl ether or $n$-heptane. Then, the mixture was decanted for $15 \mathrm{~min}$ in a separating funnel. The organic phases were evaporated and the obtained dried extracts were dissolved in $50 \mathrm{~mL}$ of water for HPLC analysis.

\subsection{HPLC-UV Analysis}

HPLC analysis was achieved with a Perkin Elmer (Series 200) system equipped with an automated sampler. A reverse phase column (Surf C18 TriF 100A $3 \mu \mathrm{m} 33 \times 4.6 \mathrm{~mm}$ ImChem) was used at $25^{\circ} \mathrm{C}$. The sample injection was $5 \mu \mathrm{L}$. The chromatographic separation was performed using an isocratic elution with a mixture of $0.1 \%(\mathrm{w})$ of acetic acid in water (solvent A) and acetonitrile (solvent B). A constant flow of solvent of $0.4 \mathrm{~mL} \cdot \mathrm{min}^{-1}$ with A/B ratio of $90 / 10(v / v)$ during 30 min was applied. Detection was accomplished with a $\mathrm{UV} / \mathrm{Visible}$ diode at a wavelength of $273 \mathrm{~nm}$ [28].

\subsection{Statistical Analysis}

Analyses were performed in duplicate. Experiments described in Section 3.3 were performed in duplicate. Linear regression was tested on the results in Section 3.2 to observe caffeine degradation during storage of wet spent coffee grounds (Figure 4). Student tests ( $t$-test) were performed with the results in Section 3.3 to evaluate the significant difference on caffeine extraction with various \% $\mathrm{EtOH}$ in hydroalcoholic solvent (Figure 6), temperature (Figure 7), time (Figure 8) and solid/liquid ratio (Figure 9). Linear regressions were tested on the results in Section 3.4 to observe the liquid/liquid extraction of caffeine with different organic solvent (Figure 10) and volume (Figure 11). Student tests ( $t$-test) were performed in Section 3.4 to evaluate the significant difference on selectivity (Figure 13) and yield (Figure 14) with various $\mathrm{pH}$ when liquid/liquid extraction of caffeine. KruskalWallis tests were carried out on the results of Section 3.2 to evaluate the significance of the influence of \% EtOH in hydroalcoholic solvent, temperature, time and solid/liquid ratio when solid/liquid extraction of caffeine (Table 1). Statistical analyses were performed with the software $\mathrm{R}$ (4.0.3 version).

\section{Results and Discussion}

\subsection{Influence of Brewing Methods}

The influence of the brewing methods on the caffeine content has been studied by comparing the caffeine content of roasted coffee beans (RCB, initial state) and of spent coffee grounds (after brewing) of different origin of roasted coffee beans and location of preparation (Figure 2). Restaurants (R1, R2, R3) have the same RCB provider and prepare coffee through percolation using professional high-pressure coffeemakers. Two different household capsule coffeemakers (C1, C2) and a mocha coffeemaker (M1) lead to coffee preparation by percolation at lower pressures. Last, filter coffeemakers (F1) only involved filtration method.

Spent coffee grounds from restaurant are richer in caffeine with $2.8-4.0 \mathrm{mg} \cdot \mathrm{g}^{-1}$ SCG; $21.5-30.8 \%$ remaining caffeine compared to the one of domestic house filtration with $0.7 \mathrm{mg} . \mathrm{g}^{-1}$ SCG; $5.6 \%$ remaining caffeine. Spent coffee grounds obtained by domestic percolation through capsule espresso $(\mathrm{C} 1, \mathrm{C} 2)$ have also revealed low concentrations of caffeine $0.5-1.1 \mathrm{mg} \cdot \mathrm{g}^{-1}$ SCG $; 2.7-9.3 \%$ of remaining caffeine. Spent coffee grounds from 
mocha apparatus (M1) exhibited a concentration of caffeine of $2.1 \mathrm{mg} \cdot \mathrm{g}^{-1}$ sCG; $16.4 \%$ remaining caffeine.
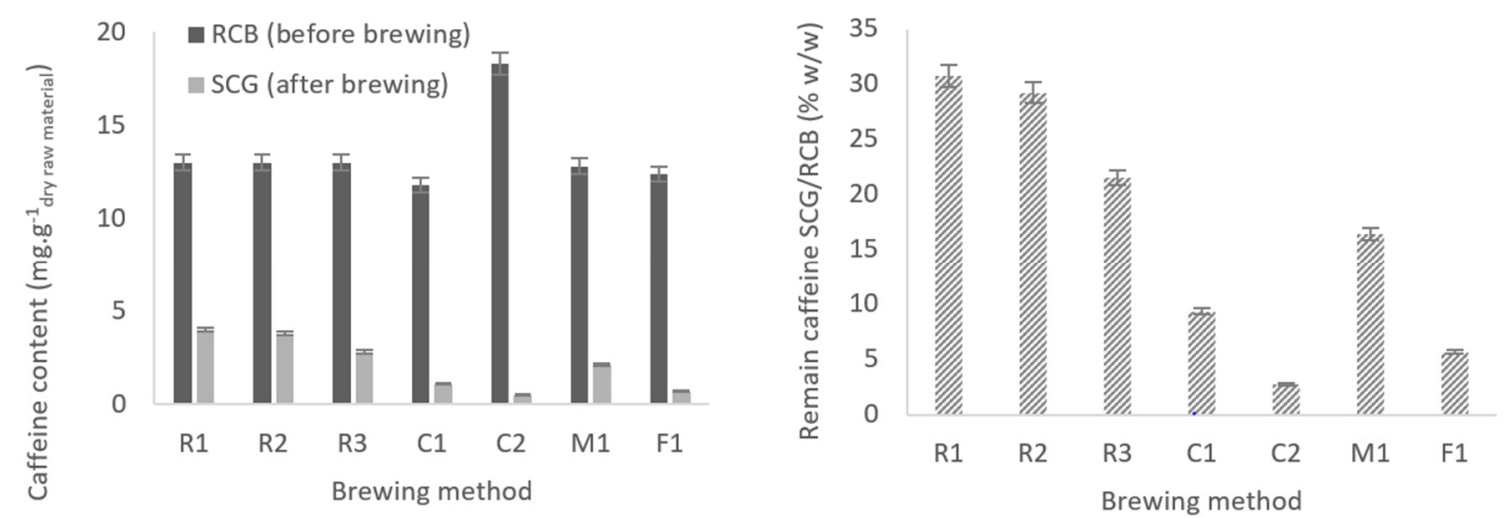

Figure 2. Caffeine content (left) in roasted coffee beans (RCB) and spent coffee grounds (SCG) and remaining caffeine SCG/RCB $(\% w / w)$ (right) as a function of the origin. A 4 h Soxhlet extraction was performed with water to totally remove the caffeine.

These preliminary results are in agreement with those of the literature, reporting that coffee beverage obtained from filtration is richer in caffeine than the coffee beverage obtained from percolation, due to longer time and bigger volume of extraction. In this work several minutes and $120 \mathrm{~mL}$ for filtration are compared to $30 \mathrm{~s}$ and $30 \mathrm{~mL}$ for percolation $[29,30]$. Thus, a selective collection of spent coffee grounds in restaurants is the most suitable for caffeine recovery [31]. This collection strategy was implemented in 2020 by the start-up "Kaffee Bueno" in Denmark that collects spent coffee grounds for free from restaurants, hotels and offices consuming over $300 \mathrm{~kg}$ of coffee per month [32]. Vakalis et al. have reported that household capsules of spent coffee grounds are the most difficult to valorize due to their high moisture level and the additional issues generated by plastic from the capsule [33].

\subsection{Influence of Spent Coffee Grounds Storage}

The influence of spent coffee grounds storage has been investigated using visual observations and measurement of caffeine content in spent coffee stored during four weeks (Figures 3 and 4).

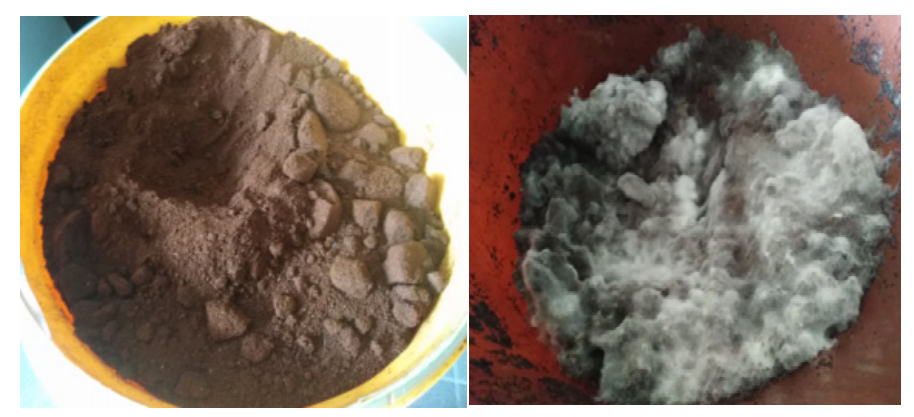

Figure 3. Spent coffee grounds after collect (left) and four weeks storage (right) in a closed bucket at room temperature. 


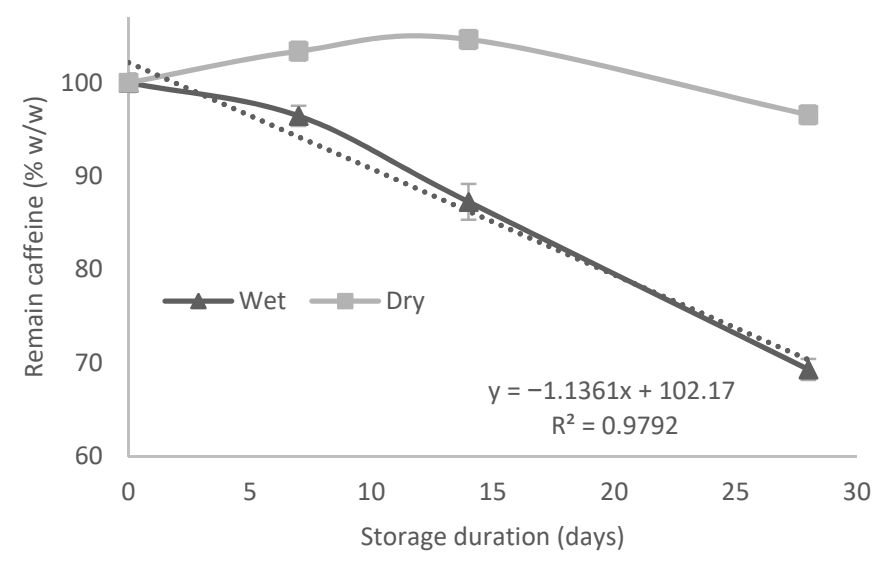

Figure 4. Evolution of the remain caffeine in wet $(\boldsymbol{\Delta})$ and dry $(\square)$ spent coffee grounds after four weeks storage in a closed flask at room temperature. A $4 \mathrm{~h}$ Soxhlet extraction has been performed with water to remove totally the caffeine.

Visual observations showed white moss that appeared at the surface of the sample revealing the growth of fungi. In the inside of raw material, wet spent coffee grounds have started to agglomerate into small balls filled with green fungus.

Experimental measurements have shown that more than $30 \%$ of caffeine in wet spent coffee grounds are degraded after 28 days when no degradation has been observed for dry spent coffee grounds. For wet spent coffee grounds, this slight decrease already appears after a week with $96.4 \%$ of not degraded caffeine. However, most significant degradation was observed after four weeks with $69.3 \%$ of remaining caffeine, in addition to a strong white moss development. Finally, the linear regression model suggests that degradation would keep going over 28 days for wet spent coffee grounds.

Batista et al. have identified Aspergillus genusas as one of filamentous fungi that develop naturally on coffee beans [34]. The mechanism of the degradation of caffeine by Aspergillus strains has been described by Gummadi et al. as successive demethylation of caffeine into 1,3-dimethylxanthine, theophylline, into 3-methylxanthine, then, into xanthine (Figure 5) [35]. Hence, main differences explaining those results between dry and wet spent coffee grounds can be related to the presence of water in the raw material, which is thus responsible for fungal development.<smiles>Cn1c(=O)c2c(ncn2C)n(C)c1=O</smiles>

Caffeine

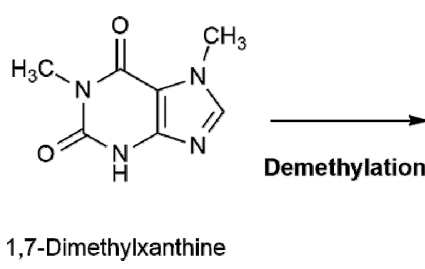

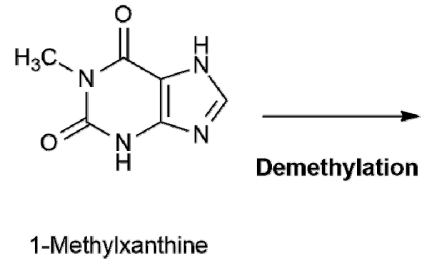

Xanthine

Figure 5. Possible mechanism of enzymatic caffeine degradation in spent coffee grounds under wet conditions, adapted from Gummadi et al. [35].

\subsection{Solid/Liquid Extraction Optimization}

The solid-liquid extraction process includes three stages: (i) permeation of the solvent through the matrix, (ii) solubilization of the solute and (iii) diffusion of the solute through the solvent [36]. Pinelo et al. have put forth the hypothesis that the limited stage in solid-liquid extraction is the diffusion of the dissolved solute (step iii). The diffusion of the solute is governed by the Fick laws [37]. Fick's first law considers that the flux of the gradient of solute concentration goes from regions of high concentration to regions of low concentration with a magnitude that is proportional to the concentration gradient (Equation (1)). 
Equation (1): Fick first law

$$
J=-D \frac{d \varphi}{d x}
$$

where $J$ is the diffusion flux expressed as amount of substance per unit area per time, $D$ is the diffusion coefficient or diffusivity expressed as area per unit time, $\varphi$ is the concentration expressed as amount of substance per unit volume and $x$ is the position expressed as the dimension of length.

Hence, several parameters of solid-liquid extraction such as the nature of the solvent, temperature, time of extraction and solid/liquid ratio $(w / v)$ or particle size can significantly affect the different stages of caffeine extraction and have been investigated. Only particle size has not been studied since spent coffee grounds is already a powder that does not need to be ground.

\subsubsection{Influence of the Nature of the Solvent}

Hydroalcoholic solutions, pure ethanol, pure water, dichloromethane and ethyl acetate were tested. The influence of hydroalcoholic solvent with different ratio EtOH/water $(0 / 100$ to $100 / 0 v / v)$ is reported in Figure 6. Optimized conditions were observed with hydroalcoholic solution at $40 \%$ ethanol ( $4.32 \mathrm{mg} \cdot \mathrm{g}^{-1} \mathrm{SCG}$ ) compared to $100 \%$ water $\left(3.63 \mathrm{mg} \cdot \mathrm{g}^{-1}\right.$ SCG) or $100 \%$ ethanol $\left(0.26 \mathrm{mg} \cdot \mathrm{g}^{-1} \mathrm{SCG}\right)$.

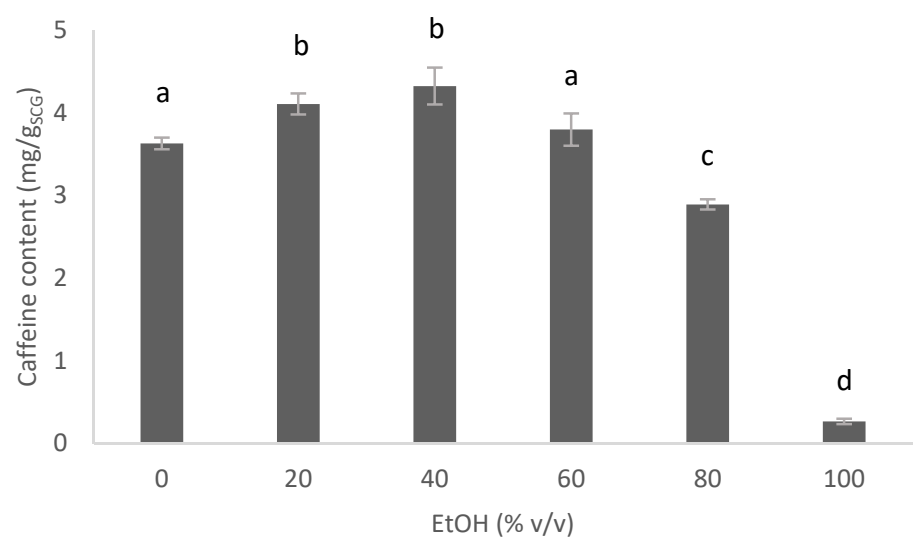

Figure 6. Influence of the $\mathrm{EtOH} /$ water ratio for the solid/liquid extraction of caffeine into spent coffee grounds (Experimental conditions: $2 \mathrm{~g}$ of SCG for $50 \mathrm{~mL}$ of hydroalcoholic solvent at $20^{\circ} \mathrm{C}$ during $15 \mathrm{~min}$, magnetically stirred). Values marked by the same letter are not significantly different $(p<0.05)$ according to the Student test $(t$-test).

As a further comparison, Santana and Macedo have determined extraction with $\mathrm{H}_{2} \mathrm{O} / \mathrm{EtOH}$ of $50 / 50(w / w)$ as optimum conditions for caffeine recovery from guarana [38]. This is in accordance with the fundamental study of the caffeine solubility in hydroalcoholic solutions by Bustamante et al. reporting a higher caffeine solubility in $\mathrm{H}_{2} \mathrm{O} / \mathrm{EtOH}$ with a $40 / 60$ ratio $(v / v)$ between 5 and $40{ }^{\circ} \mathrm{C}$ [39].

Zosel has patented a caffeine extraction system with supercritical $\mathrm{CO}_{2}$ at temperatures between 40 and $80^{\circ} \mathrm{C}$, and pressures between 120 and $180 \mathrm{~atm} ; 5$ to $30 \mathrm{~h}$ were required to quantitatively extract the caffeine [40]. Todd and Baroutian have reported a comparative techno-economic analysis of the extraction of bioactive grape marc using supercritical $\mathrm{CO}_{2}$ vs. organic solvent extraction [41]. The costs of manufacture (COM) have been reported as 87.0 NZ\$/ton for organic solvents and $123.40 \mathrm{NZ \$ /ton} \mathrm{for} \mathrm{supercritical} \mathrm{CO}_{2}$; these results show that supercritical $\mathrm{CO}_{2}$ is a more expensive process [41]. The decaffeination using supercritical $\mathrm{CO}_{2}$ is efficient, highly selective and eco-responsible for coffee bean without removing flavor. Unfortunately, the additional cost can seem questionable when it comes to treating waste. Indeed, the residue after extraction is presently without market value. 
The extracted caffeine for dichloromethane $\left(1.7 \mathrm{mg} \cdot \mathrm{g}^{-1} \mathrm{SCG}\right)$ and ethyl acetate (0.5 mg. ${ }^{-1}$ SCG) are worse than optimized hydroalcoholic solution $\left(4.32 \mathrm{mg}^{-\mathrm{g}^{-1}}\right.$ SCG). This is surprising since Shalmashi et al. have reported that caffeine solubility was higher in dichloromethane and chloroform compared to water, ethyl acetate, ethanol, carbon tetrachloride, methanol and acetone [42]. However, according to Sondheimer et al., caffeine occurs in coffee as chlorogenic acid-caffeine complex where it is hardly extractible with chloroform [43]. Hence, a polar solvent such as water-based solvent is strongly recommended for effective extraction of caffeine from coffee matrices in short time. In addition, Bustamante et al. have highlighted that caffeine display several functional groups with different hydrogen bonding abilities, explaining the affinity for water-based solvent [39]. Hence, we can make the hypothesis that ethanol can decrease the polarity of water, while keeping strong hydrogen bonding interactions between water and caffeine. The Student test does not show that an increase of the $\mathrm{EtOH}$ content in the hydroalcoholic solvent from $20 \%$ to $40 \%$ increases caffeine extraction efficiency $(p<0.05)$. Therefore, extractions could be performed with $20 \% \mathrm{EtOH}$ to minimize the proportion of organic solvent. In our case, the following experiments were performed with hydroalcoholic solvent with $40 \%$ ethanol.

\subsubsection{Influence of the Extraction Temperature}

Temperature influence between ambient temperature $\left(20^{\circ} \mathrm{C}\right)$ and temperature close to ethanol boiling point $\left(80^{\circ} \mathrm{C}\right)$ was investigated on caffeine extraction (Figure 7). A slight increase $(+11 \%)$ was observed between $20{ }^{\circ} \mathrm{C}\left(4.23 \mathrm{mg} \cdot \mathrm{g}^{-1} \mathrm{SCG}\right)$ and $60-80{ }^{\circ} \mathrm{C}$ (4.67-4.76 mg.g ${ }^{-1}$ SCG).

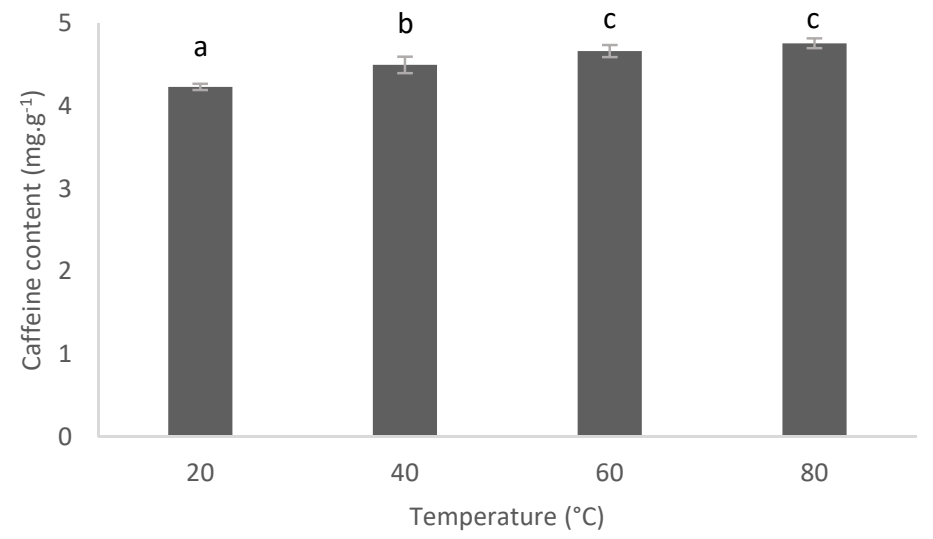

Figure 7. Influence of the temperature for the solid/liquid extraction of caffeine into spent coffee grounds (Experimental conditions: $2 \mathrm{~g}$ of SCG for 50. $\mathrm{mL}$ of $\mathrm{H}_{2} \mathrm{O} / \mathrm{EtOH}(60 / 40 \mathrm{v} / \mathrm{v})$, during $15 \mathrm{~min}$, magnetically stirred). Values marked by the same letter are not significantly different $(p<0.05)$ according to the Student test ( $t$-test).

Linares et al. have found that a temperature between 40 and $70{ }^{\circ} \mathrm{C}$ did not affect the equilibrium concentration and extraction yield of yerba mate after $60 \mathrm{~min}$ of extraction [44]. Hence, the temperature influenced the kinetic parameters since the pseudo first order kinetic constant $\left(\mathrm{k}_{\mathrm{obs}}\right)$ and effective diffusion coefficient $\left(\mathrm{D}_{\text {leaf }}\right)$ were higher at $70{ }^{\circ} \mathrm{C}$ with $\mathrm{k}_{\text {obs }}=3.155 \times 10^{3} \mathrm{~s}^{-1}, \mathrm{D}_{\text {leaf }}=9469 \times 10^{11} \mathrm{~m}^{2} \cdot \mathrm{s}^{-1}$ compared to $40^{\circ} \mathrm{C}$ extraction with $\mathrm{k}_{\mathrm{obs}}=2.030 \times 10^{3} \mathrm{~s}^{-1}, \mathrm{D}_{\text {leaf }}=6092 \times 10^{11} \mathrm{~m}^{2} \cdot \mathrm{s}^{-1}$. The experiments that were performed (Figure 7) showed similar trends with an incomplete extraction at $20{ }^{\circ} \mathrm{C}$ compared to $60-80^{\circ} \mathrm{C}$. In addition, caffeine is a very stable molecule even at high temperature, as reported by Shalmashi et al. [45]. The Student test does not show that an increase of the temperature from $60^{\circ} \mathrm{C}$ to $80^{\circ} \mathrm{C}$ increase caffeine extraction efficiency $(p<0.05)$. Therefore, extractions were performed at $60^{\circ} \mathrm{C}$ to reduce energy consumption. 


\subsubsection{Influence of the Extraction Time}

The time of extraction influence was investigated on caffeine extraction, but similar results were observed from 5 to $15 \mathrm{~min}$ of extraction (Figure 8).

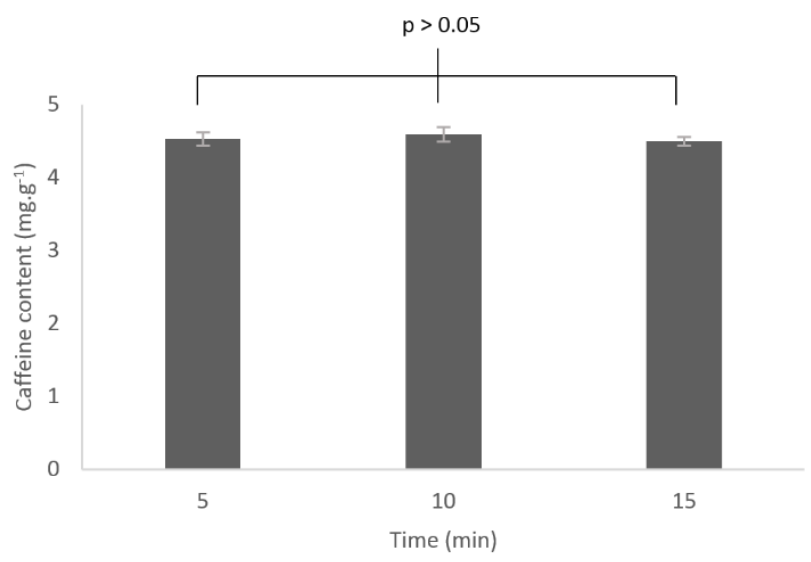

Figure 8. Influence of the time for the solid/liquid extraction of caffeine into spent coffee grounds (Experimental conditions: $2 \mathrm{~g}$ of SCG for $50 \mathrm{~mL}$ of $\mathrm{H}_{2} \mathrm{O} / \mathrm{EtOH}(60 / 40)$, at $60{ }^{\circ} \mathrm{C}$, magnetically stirred). All values are not significantly different $(p<0.05)$ according to the Student test $(t$-test).

Lee et al. observed similar trends for black tea extraction with water at $25{ }^{\circ} \mathrm{C}$. The fast caffeine extraction might be due to an easy accessibility of spent coffee grounds that is enhanced by the powder shape of spent coffee grounds due to the grinding step, like the rolling step for black tea preparation [46]. The Student test did not show that times of extraction of 5,10 or 15 min lead to significant extraction efficiency increase $(p<0.05)$. Therefore, extraction was performed in $5 \mathrm{~min}$ to reduce energy consumption. However, solid/liquid ratio experiments were performed in $15 \mathrm{~min}$ to more easily evaluate their influence.

\subsubsection{Influence of the Solid/Liquid Ratio}

The solid/liquid ratio (5-35 mL.g ${ }^{-1}$ ) of caffeine extraction was studied (Figure 9) The major difference was observed between $5 \mathrm{~mL} \cdot \mathrm{g}^{-1}$ (2.35 mg.g ${ }^{-1}$ sCG) and $15 \mathrm{~mL} \cdot \mathrm{g}^{-1}$ (3.23 mg. $\left.\mathrm{g}^{-1} \mathrm{SCG}\right)$. The Student test does not show that a variation of the solid/liquid ratio from 15 to $25 \mathrm{~mL} \cdot \mathrm{g}^{-1}$ significantly increase caffeine extraction $(p<0.05)$. The experiments could be therefore performed with a $15 \mathrm{~mL} \cdot \mathrm{g}^{-1}$ ratio in order to reduce solvent consumption.

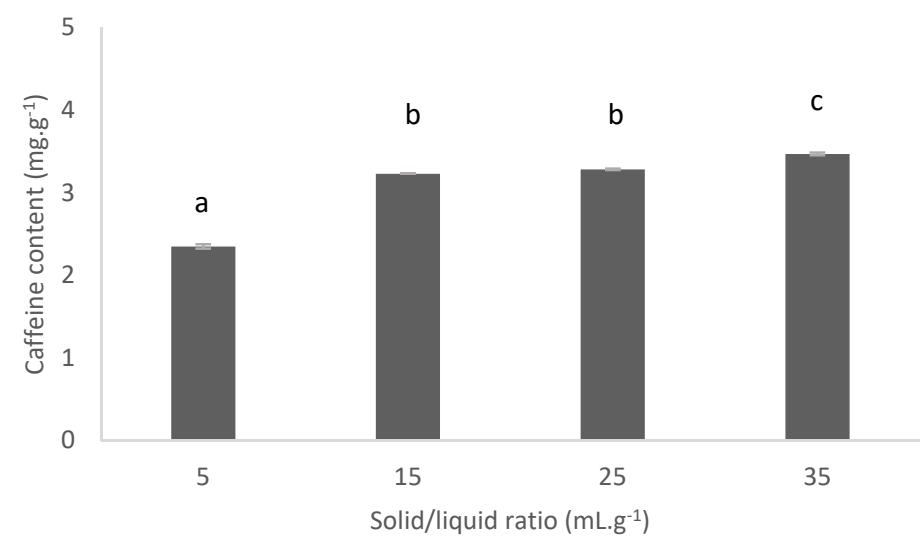

Figure 9. Influence of the solid/liquid ratio for the solid/liquid extraction of caffeine into spent coffee grounds. (Experimental conditions: $2 \mathrm{~g}$ of SCG for $50 \mathrm{~mL}$ of $\mathrm{H}_{2} \mathrm{O} / \mathrm{EtOH}(60 / 40)$ ), at $60{ }^{\circ} \mathrm{C}$ during $15 \mathrm{~min}$, magnetically stirred). Values marked by the same letter are not significantly different $(p<0.05)$ according to the Student test $(t$-test $)$. 
Ho Row et al. investigated the influence of solid/liquid ratio from 5 to $60 \mathrm{~mL} . \mathrm{g}^{-1}$ in decaffeination of coffee bean waste with $\mathrm{EtOH} / \mathrm{H}_{2} \mathrm{O} 50 / 50(v / v)$ at $80^{\circ} \mathrm{C}$ during $60 \mathrm{~min}$ [47]. They reported an increase of the decaffeination with bigger volume of extraction. More precisely, up to $78 \%, 92 \%$ and $98 \%$ of caffeine were extracted with 5,10 and $20 \mathrm{~mL}$ per gram, respectively. According to the authors, when the amount of solvent increases, the chance of bioactive components coming into contact with the solvent goes up, leading to higher leaching out rates. In addition, the bad diffusion of solutes cannot be compensated by strong agitation since Silva et al. have observed weak influence of stirring $(0-400 \mathrm{rpm})$ on the yield of extraction [48].

Kruskal-Wallis comparative analysis of the influence of the different factors is summarized in Table 1. The results show, with a probability superior to $99.9 \%$, that solvent and temperature significantly influence caffeine extraction in the range of values that has been studied.

Table 1. Kruskal-Wallis test of influencing parameters during solid/liquid extraction of spent coffee grounds.

\begin{tabular}{cccc}
\hline & $\begin{array}{c}\text { Kruskal-Wallis } \\
\text { Chi-Squared }\end{array}$ & $\begin{array}{c}\text { Degree of Freedom } \\
(\mathbf{f d})\end{array}$ & $\begin{array}{c}\text { Probability Value } \\
(\boldsymbol{p} \text {-Value })\end{array}$ \\
\hline Solvent & 22.044 & 5 & 0.0005136 \\
\hline Temperature & 20.022 & 3 & 0.000168 \\
\hline Time & 6.1869 & 2 & 0.04535 \\
\hline Solid/Liquid ratio & 9.0544 & 3 & 0.02858 \\
\hline
\end{tabular}

\subsection{Purification of Caffeine by Liquid/Liquid Extraction}

The solid/liquid extract is rich in caffeine and impurities such as polyphenols, melanoidins and other polar molecules. To purify caffeine, a liquid/liquid extraction step is required. Instead of hydroalcoholic extracts, water extracts have been used for this study to simplify the liquid/liquid extraction. Hence, the following results can be extrapolated to hydroalcoholic extracts that can be evaporated and solubilized into water. This part will focus on the optimization of liquid/liquid extraction such as nature and volume of organic solvent and $\mathrm{pH}$ of aqueous phase.

\subsubsection{Influence of Different Organic Solvents for Liquid/Liquid Extraction of Caffeine}

The choice of the organic solvent is the most important parameter in a liquid/liquid extraction [49]. It should be immiscible with the aqueous phase and the solutes need a higher affinity for the solvent of extraction to be recovered. It is measured as $\mathrm{K}$, the coefficient distribution/partition, provided in Equation (2).

Equation (2): Distribution/Partition coefficient in liquid/liquid extraction.

$$
K_{\text {solvent }}=\frac{\text { Solute concentration in organic phase (extraction solvent) }}{\text { Solute concentration in aqueous/hydroalcoholic phase (original solution) }}
$$

Since the distribution coefficient is a ratio, unless $K$ is very large, a single extraction is not enough to extract all the solute. A multiple extraction is recommended, that is, in different steps, at equilibrium, the solute has the same partition/distribution coefficient $K$. Then, to perform liquid/liquid extraction in appropriate conditions, the volume of extraction has been split into six small extractions of $10 \mathrm{~mL}$ instead of a unique extraction of $60 \mathrm{~mL}$.

Among the organic solvents with immiscibility for water, dichloromethane, ethyl acetate, diethyl ether and $n$-heptane have been tested (Figure 10). Diethyl ether and $n$ heptane are not reported in Figure 10 since no caffeine was recovered in these solvents. Interestingly, Table 2 shows that dichloromethane or ethyl acetate have the dipolar moment 
and the Hildebrand function the closest of those of caffeine, and are the solvents the most appropriate here for the transfer of caffeine.

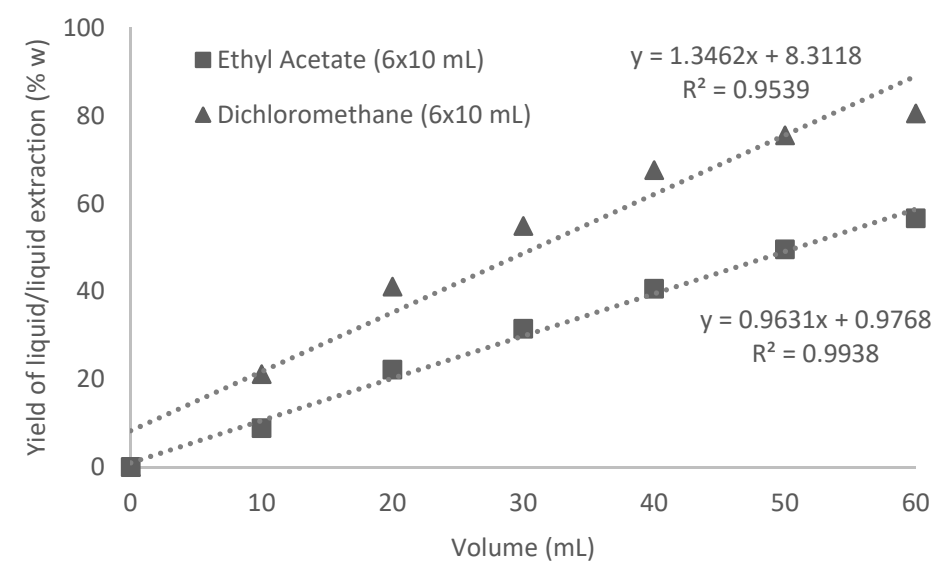

Figure 10. Evolution of the yield of caffeine transferred $(\% \mathrm{w})$ from aqueous extract $(60 \mathrm{~mL})$ into $6 \times 10 \mathrm{~mL}$ of dichloromethane $(\boldsymbol{\Delta})$ or ethyl acetate $(\boldsymbol{\square})$ during liquid/liquid extraction at room temperature.

Table 2. Dipolar moment $\mu$ and Hildebrand function $\delta$ of caffeine and organic solvents for liquid/liquid extraction [50-53].

\begin{tabular}{ccc}
\hline & $\begin{array}{c}\text { Dipolar Moment } \\
\mu \text { (Debye) }\end{array}$ & $\begin{array}{c}\text { Hildebrand Function } \\
\boldsymbol{\delta}\left(\mathbf{c a l} / \mathbf{c m}^{\mathbf{3}}\right)^{\mathbf{1 / 2}}\end{array}$ \\
\hline Caffeine & 3.46 & 13.8 \\
\hline Dichloromethane & 1.600 & 9.93 \\
\hline Ethyl acetate & 1.780 & 9.10 \\
\hline Diethyl ether & 1.098 & 7.62 \\
\hline n-heptane & 0 & 7.4 \\
\hline
\end{tabular}

After six cycles, $80 \%$ of caffeine transferred (Equation (3)) in dichloromethane instead of $57 \%$ in ethyl acetate.

Equation (3): Yield of liquid/liquid extraction.

$$
\text { Yield }_{\text {liquid/liquid }}=\frac{\text { Amount of caffeine in organic phase }}{\text { Amount of caffeine in aqueous extract }} .
$$

Mohammed et al. have performed liquid/liquid extraction of caffeine with dichloromethane, since it is the most widely used solvent for decaffeination. Their experience allowed recovering 98 to $99 \%$ of caffeine [54]. The efficiency of dichloromethane compared to ethyl acetate is supported by the experimental measurements of mole fraction solubility of caffeine in dichloromethane that is 10 times higher than the one in ethyl acetate [42]. However, due to green chemistry concerns it is more suitable to use an eco-compatible solvent such as ethyl acetate. In addition, ethyl acetate extraction curve follows a linear regression model. This suggests that caffeine extraction has not yet reach a plateau for the maximum ethyl acetate volume that was used in the present study.

\subsubsection{Influence of the Volume of Extraction Solvent}

The influence of the volume of ethyl acetate with $6 \times 30 \mathrm{~mL}$ compared to $6 \times 10 \mathrm{~mL}$ to treat $60 \mathrm{~mL}$ of aqueous extract has been reported during liquid/liquid extraction (Figure 11). The curve of the yield has shown quite linear increases even up to $6 \times 30 \mathrm{~mL}$ of ethyl acetate. Better results with $6 \times 30 \mathrm{~mL}$ have reached $93.4 \%$ of extraction yield. By increasing 
the volume, solvent of extraction is not saturated in solute, thus, coefficient distribution is increased in favor of the solvent of extraction. Results with $6 \times 30 \mathrm{~mL}$ of ethyl acetate are competitive with those obtained with $6 \times 10 \mathrm{~mL}$ of dichloromethane.

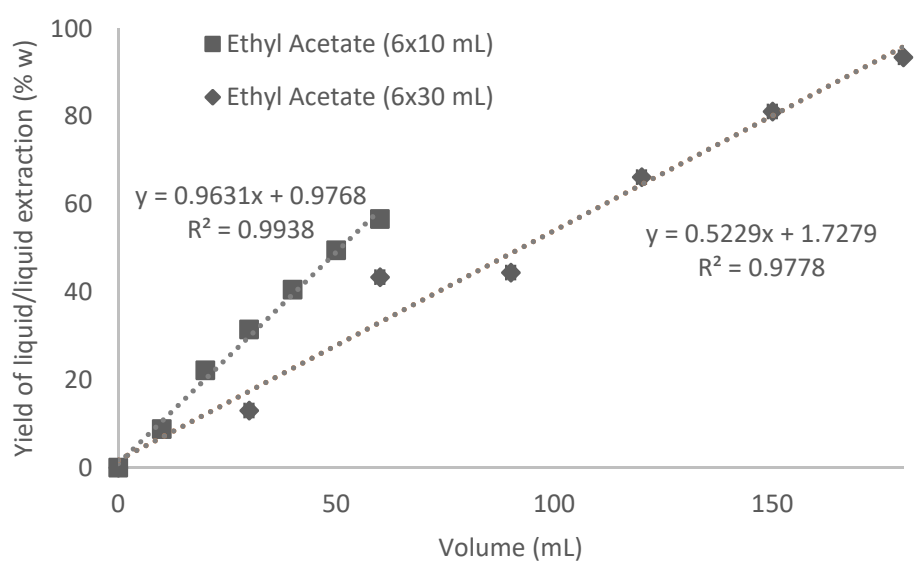

Figure 11. Evolution of the yield of caffeine transferred $(\% \mathrm{w})$ from aqueous extract $(60 \mathrm{~mL})$ into $6 \times 10 \mathrm{~mL}(\boldsymbol{\square})$ or $6 \times 30 \mathrm{~mL}$ ethyl acetate

\subsubsection{Influence of Aqueous Extract $\mathrm{pH}$}

The influence of the $\mathrm{pH}$ of the solution is an important parameter that can affect both, yield and selectivity of the liquid/liquid extraction of caffeine. The affinity of caffeine for the aqueous or organic phase is strongly related to the different $\mathrm{pKa}$ of caffeine and $\mathrm{pH}$ of the aqueous phase. Charged molecules have better affinity to aqueous phase through hydrogen bonds. The selectivity can be observed indirectly through the area ratio of caffeine in chromatograms (Equation (4)).

Equation (4): Area ratio of caffeine.

$$
\text { Area ratio of caffeine }=\frac{\text { Area of caffeine peak in the chromatogram extract at } 273 \mathrm{~nm}}{\text { Area of all the peaks in the chromatogram extract at } 273 \mathrm{~nm}}
$$

The influence of $\mathrm{pH}$ on the selectivity and yield has been illustrated through the analysis of chromatograms (Figure 12), the area ratio of caffeine (Figure 13) and yields of extractions (Figure 14).

The observation of chromatograms after liquid/liquid extraction was reported. Ethyl acetate was yellow colored after liquid/liquid extractions performed at $\mathrm{pH}=2$ and 7 and colorless at $\mathrm{pH}$ of 14 . At $\mathrm{pH}=2$ and $\mathrm{pH}=7$, the chromatograms contain several peaks with moderate to high intensity in addition of caffeine (Figure 12). By contrast, at $\mathrm{pH}=14$, chromatogram contains only the peak of caffeine peak (Figure 12). This results in an area ratio of caffeine described in Equation (4) that is higher at $\mathrm{pH}=14$ than at $\mathrm{pHs}=2$ and 7, indirectly indicating a higher purity (Figure 13). In accordance with those observations, Student tests show significant differences between the values of the area ratio of caffeine (Equation (4)) at different $\mathrm{pH}(p<0.05)$. On the other hand, Student tests do not show significant difference on the yield of caffeine transferred in ethyl acetate as a function of $\mathrm{pH}(p<0.05)$. To conclude, statistical analyses of the $\mathrm{pH}$ influence unequivocally suggest that $\mathrm{pH}$ exclusively affects the selectivity of the liquid/liquid extraction of caffeine. 


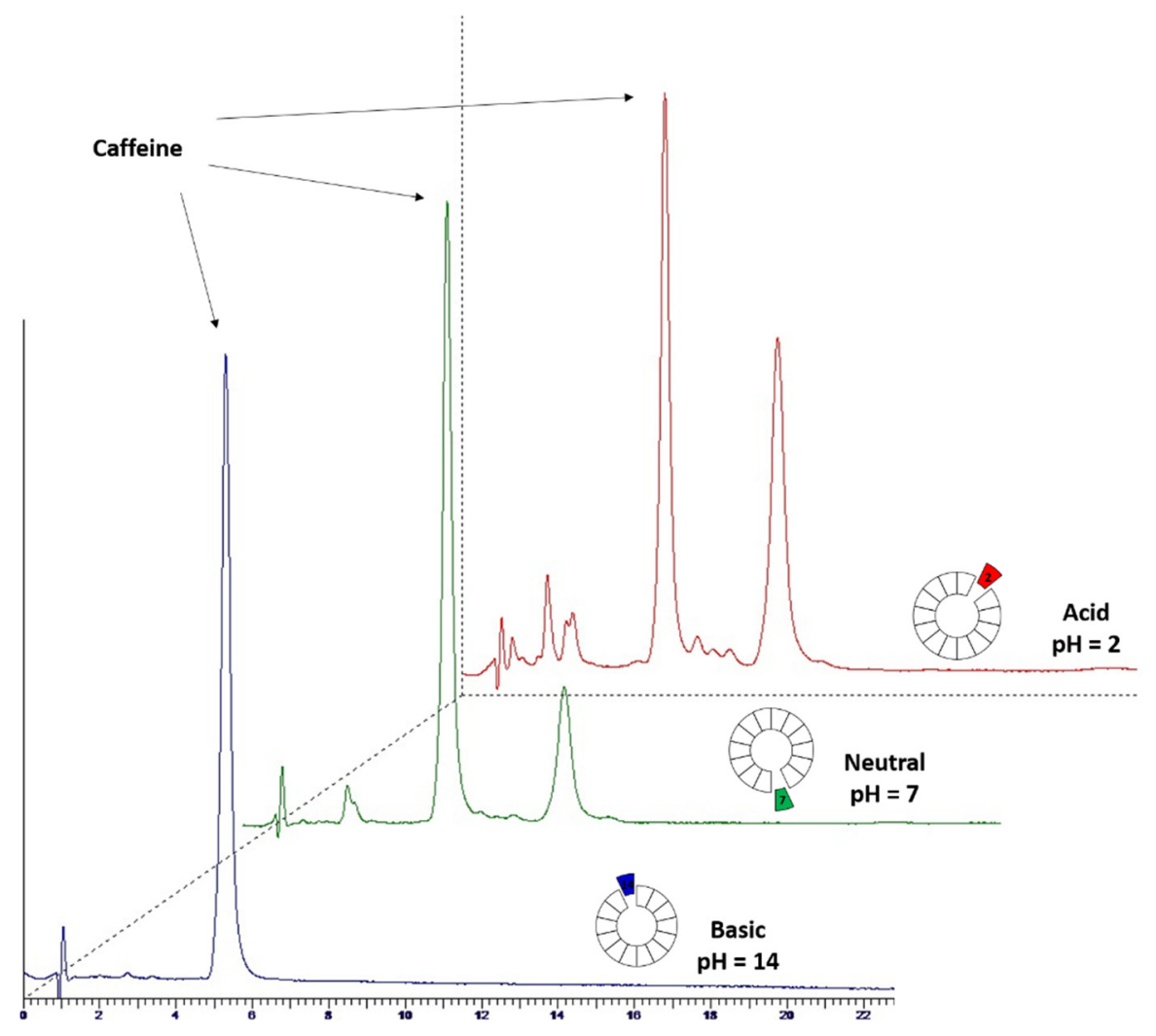

Figure 12. Chromatograms of caffeine and impurities transferred in ethyl acetate at $\mathrm{pH}=2$ (red, behind), $\mathrm{pH}=7$ (green, middle) and $\mathrm{pH}=14$ (blue, forward) during liquid/liquid extraction at room temperature.

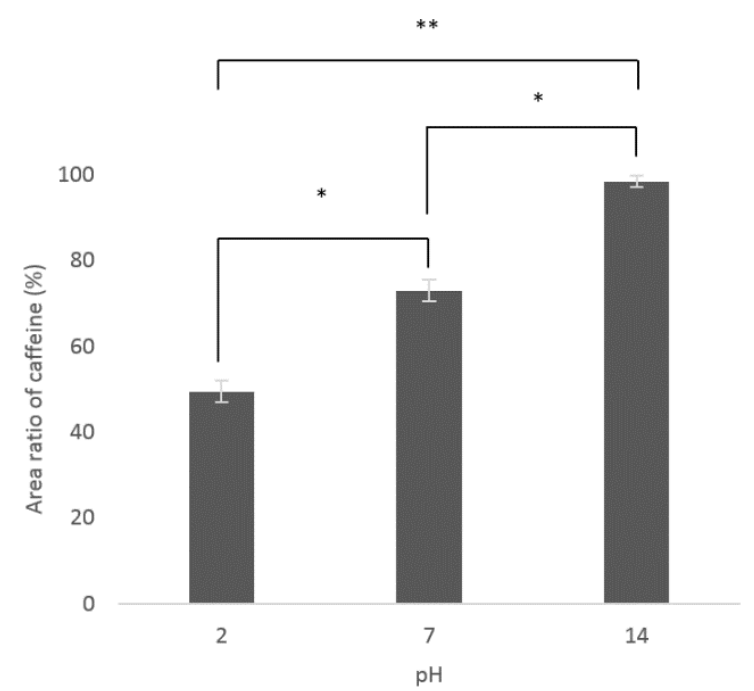

Figure 13. Influence of the $\mathrm{pH}$ on the area ratio of caffeine of liquid/liquid extraction of aqueous extract $(60 \mathrm{~mL})$ treated with ethyl acetate $(60 \mathrm{~mL})$ at room temperature. Values marked by the symbol * are significantly different $(p<0.05)$ according to the Student test $(t$-test). Values marked by the symbol ${ }^{* *}$ are significantly different $(p<0.01)$ according to the Student test $(t$-test). 


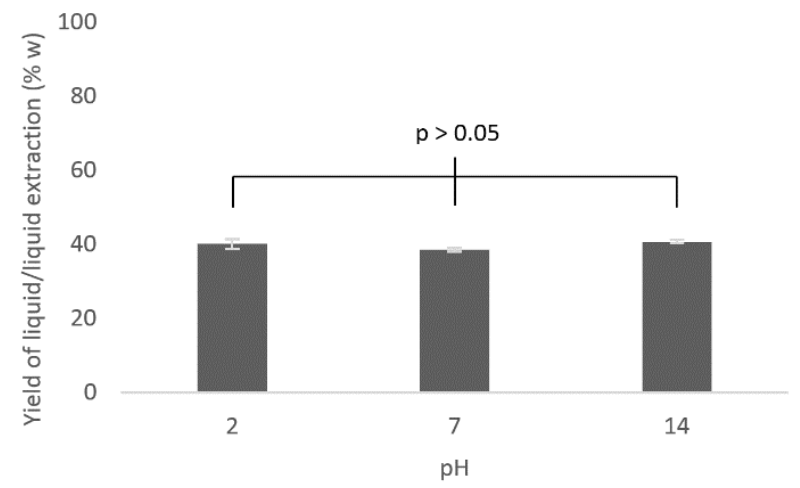

Figure 14. Influence of the $\mathrm{pH}$ on the yield of liquid/liquid extraction of aqueous extract $(60 \mathrm{~mL})$ treated with ethyl acetate $(60 \mathrm{~mL})$ at room temperature. All the values are not significantly different $(p<0.05)$ according to the Student test $(t$-test).

Polyphenols like chlorogenic acids are the main impurities in aqueous extract, thus, potentially transferred in ethyl acetate $[55,56]$. Gazzani et al. have reported that chlorogenic acids from green coffee beans were more efficiently extracted in ethyl acetate at acidic $\mathrm{pH}$ [57]. This might due to the lack of affinity of protonated form of chlorogenic acids since their $\mathrm{pKa}$ are $\mathrm{pKa}_{1}=3.50, \mathrm{pKa}_{2}=8.42$ and $\mathrm{pKa}_{3}=11.00$ [58]. For our experimental results, at $\mathrm{pH}=2$ and 7 , the $-\mathrm{OH}$ function of chlorogenic acids stayed in a totally or partially protonated form, which resulted in lower affinity for aqueous phase and higher transfer in ethyl acetate. At $\mathrm{pH}=14$, all the $-\mathrm{OH}$ functions of chlorogenic acids were deprotonated into $-\mathrm{O}^{-}$, which favored hydrogen bonds with aqueous phase, resulting in none transfer of chlorogenic acids in ethyl acetate.

Caffeine has low interaction with aqueous phase at $\mathrm{pH}=2,7$ and 14 since caffeine $\mathrm{pKa}$ are $\mathrm{pKa}_{1}=0.6-0.7$ and $\mathrm{pKa}_{2}=14$ (Figure 15) [59-61]. This results in a similar yield of caffeine transferred at all the studied $\mathrm{pH}$ (Figure 14).
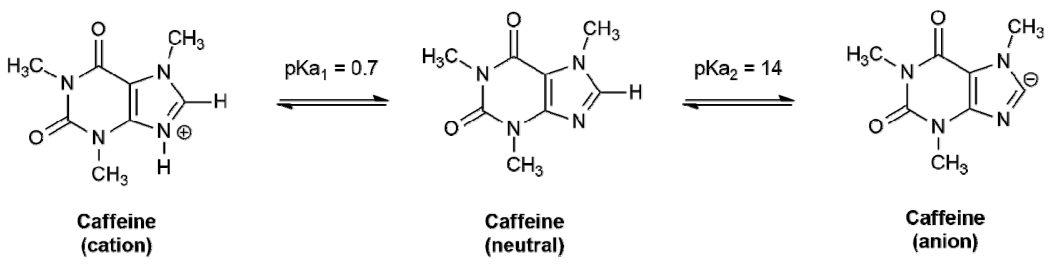

Figure 15. Acid/base equilibrium of caffeine.

No experiment has been carried out with $\mathrm{pH}<0.7$ and $\mathrm{pH} \geq 14$ to confirm that caffeine cation or anion has more affinity for water.

\section{Conclusions}

The present study promotes the valorization of the most popular food waste, spent coffee grounds, into caffeine molecule, presenting a well-established market for applications in agrifood, cosmetic, nutraceutic or pharmaceutic industries. This paper proposes a complete investigation and optimization for the production of caffeine from spent coffee grounds, including all key steps such as collection, storage, solid/liquid extraction and purification by liquid/liquid extraction.

Investigation of collection has shown that spent coffee grounds from restaurants are richer in caffeine with $30 \%$ remaining caffeine. Studies on storage have reported that drying is an unnecessary step when spent coffee grounds extractions are performed below one week of storage because degradation of caffeine is lower than $4 \%$. Investigation of solid/liquid extraction indicates that extraction of $2 \mathrm{~g}$ with $50 \mathrm{~mL}$ hydroalcoholic solvent $40 \% \mathrm{EtOH}$ and $25 \mathrm{~mL} \cdot \mathrm{g}^{-1}$ solid/liquid ratio at $60{ }^{\circ} \mathrm{C}$ during $5 \mathrm{~min}$ are the optimized conditions. Investigation of caffeine purification by liquid/liquid extraction illustrates that 
extraction of $60 \mathrm{~mL}$ of aqueous phase at $\mathrm{pH}=12-14$ with $6 \times 30 \mathrm{~mL}$ of green solvent like ethyl acetate is efficient to recover $93.4 \%$ of purified caffeine.

In accordance with circular economy and the need to $100 \%$ waste valorization, further studies will be carry out to perform (i) the valorization of decaffeinated extract that is rich in polyphenols $[18,62]$ and (ii) the valorization of solid coffee residue after hydroalcoholic extractions that is a rich lignocellulose and lipid material [4,5].

Author Contributions: Experimental work at lab, A.V.; writing—original draft preparation, A.V.; writing-review and editing, A.V., M.D., C.P., G.C.; Student supervision, M.D., C.P., G.C.; project coordination, G.C. All authors have read and agreed to the published version of the manuscript.

Funding: The authors gratefully acknowledge the Auvergne Rhône Alpes French Region for the awarding of the PhD scholarship to Alexandre Vandeponseele and for equipment funding through the Pack Ambition Recherche program. They also acknowledge the TRIALP company and the Université Savoie Mont Blanc Foundation for their financial supports through soMAR project.

Acknowledgments: The authors warmly acknowledge David Gateuille and Lise Marchal for their help in performing statistical analyses.

Conflicts of Interest: The authors declare no conflict of interest.

\section{References}

1. International Coffee Organization. Available online: http://www.ico.org/ (accessed on 4 October 2020).

2. Pfluger, R.A. Soluble coffee processing. In Solid Wastes Origin Collection Processing \& Disposal. Cl Mantell; Wiley: New York, NY, USA, 1975.

3. Liu, Y.; Tu, Q.; Knothe, G.; Lu, M. Direct transesterification of spent coffee grounds for biodiesel production. Fuel 2017, 199, 157-161. [CrossRef]

4. Caetano, N.S.; Silva, V.F.; Mata, T.M. Valorization of coffee grounds for biodiesel production. Chem. Eng. Trans. 2012, 26. [CrossRef]

5. Kwon, E.E.; Yi, H.; Jeon, Y.J. Sequential co-production of biodiesel and bioethanol with spent coffee grounds. Bioresour. Technol. 2013, 136, 475-480. [CrossRef] [PubMed]

6. Choi, I.S.; Wi, S.G.; Kim, S.-B.; Bae, H.-J. Conversion of coffee residue waste into bioethanol with using popping pretreatment. Bioresour. Technol. 2012, 125, 132-137. [CrossRef] [PubMed]

7. Obruca, S.; Benesova, P.; Petrik, S.; Oborna, J.; Prikryl, R.; Marova, I. Production of polyhydroxyalkanoates using hydrolysate of spent coffee grounds. Process Biochem. 2014, 49, 1409-1414. [CrossRef]

8. Cruz, M.V.; Paiva, A.; Lisboa, P.; Freitas, F.; Alves, V.D.; Simões, P.; Barreiros, S.; Reis, M.A. Production of polyhydroxyalkanoates from spent coffee grounds oil obtained by supercritical fluid extraction technology. Bioresour. Technol. 2014, 157, 360-363. [CrossRef] [PubMed]

9. Plaza, M.; González, A.; Pevida, C.; Pis, J.; Rubiera, F. Valorisation of spent coffee grounds as $\mathrm{CO}_{2}$ adsorbents for postcombustion capture applications. Appl. Energy 2012, 99, 272-279. [CrossRef]

10. Cerino-Córdova, F.; Díaz-Flores, P.; García-Reyes, R.; Soto-Regalado, E.; Gómez-González, R.; Garza-González, M.; BustamanteAlcántara, E. Biosorption of $\mathrm{Cu}$ (II) and $\mathrm{Pb}$ (II) from aqueous solutions by chemically modified spent coffee grains. Int. J. Environ. Sci. Technol. 2013, 10, 611-622. [CrossRef]

11. Acevedo, F.; Rubilar, M.; Scheuermann, E.; Cancino, B.; Uquiche, E.; Garcés, M.; Inostroza, K.; Shene, C. Spent coffee grounds as a renewable source of bioactive compounds. J. Biobased Mater. Bioenergy 2013, 7, 420-428. [CrossRef]

12. Magalhães, L.M.; Machado, S.; Segundo, M.A.; Lopes, J.A.; Páscoa, R.N. Rapid assessment of bioactive phenolics and methylxanthines in spent coffee grounds by FT-NIR spectroscopy. Talanta 2016, 147, 460-467. [CrossRef]

13. Ribeiro, H.M.; Allegro, M.; Marto, J.; Pedras, B.; Oliveira, N.G.; Paiva, A.; Barreiros, S.; Gonçalves, L.D.M.; Simões, P. Converting spent coffee grounds into bioactive extracts with potential skin antiaging and lightening effects. Acs Sustain. Chem. Eng. 2018, 6, 6289-6295. [CrossRef]

14. Scully, D.; Jaiswal, A.; Abu-Ghannam, N. An investigation into spent coffee waste as a renewable source of bioactive compounds and industrially important sugars. Bioengineering 2016, 3, 33. [CrossRef] [PubMed]

15. Bravo, J.; Monente, C.; Juániz, I.; De Peña, M.P.; Cid, C. Influence of extraction process on antioxidant capacity of spent coffee. Food Res. Int. 2013, 50, 610-616. [CrossRef]

16. Andrade, K.S.; Gonçalvez, R.T.; Maraschin, M.; Ribeiro-do-Valle, R.M.; Martínez, J.; Ferreira, S.R. Supercritical fluid extraction from spent coffee grounds and coffee husks: Antioxidant activity and effect of operational variables on extract composition. Talanta 2012, 88, 544-552. [CrossRef]

17. Mussatto, S.I.; Ballesteros, L.F.; Martins, S.; Teixeira, J.A. Extraction of antioxidant phenolic compounds from spent coffee grounds. Sep. Purif. Technol. 2011, 83, 173-179. [CrossRef] 
18. Panusa, A.; Zuorro, A.; Lavecchia, R.; Marrosu, G.; Petrucci, R. Recovery of natural antioxidants from spent coffee grounds. J. Agric. Food Chem. 2013, 61, 4162-4168. [CrossRef]

19. Getachew, A.T.; Cho, Y.J.; Chun, B.S. Effect of pretreatments on isolation of bioactive polysaccharides from spent coffee grounds using subcritical water. Int. J. Biol. Macromol. 2018, 109, 711-719. [CrossRef]

20. Ballesteros, L.F.; Teixeira, J.A.; Mussatto, S.I. Extraction of polysaccharides by autohydrolysis of spent coffee grounds and evaluation of their antioxidant activity. Carbohydr. Polym. 2017, 157, 258-266. [CrossRef]

21. Vandeponseele, A.; Draye, M.; Piot, C.; Chatel, G. Subcritical water and supercritical carbon dioxide: Efficient and selective eco-compatible solvents for coffee and coffee by-products valorization. Green Chem. 2020, 22, 8544-8571. [CrossRef]

22. Juliano, L.M.; Griffiths, R.R. A critical review of caffeine withdrawal: Empirical validation of symptoms and signs, incidence, severity, and associated features. Psychopharmacology 2004, 176, 1-29. [CrossRef]

23. McCusker, R.R.; Goldberger, B.A.; Cone, E.J. Caffeine content of energy drinks, carbonated sodas, and other beverages. J. Anal. Toxicol. 2006, 30, 112-114. [CrossRef] [PubMed]

24. Renner, B.; Clarke, G.; Grattan, T.; Beisel, A.; Mueller, C.; Werner, U.; Kobal, G.; Brune, K. Caffeine accelerates absorption and enhances the analgesic effect of acetaminophen. J. Clin. Pharmacol. 2007, 47, 715-726. [CrossRef] [PubMed]

25. Byun, S.-Y.; Kwon, S.-H.; Heo, S.-H.; Shim, J.-S.; Du, M.-H.; Na, J.-I. Efficacy of slimming cream containing 3.5\% water-soluble caffeine and xanthenes for the treatment of cellulite: Clinical study and literature review. Ann. Dermatol. 2015, 27, 243-249. [CrossRef] [PubMed]

26. Pietsch, A. Decaffeination—Process and Quality. In The Craft and Science of Coffee; Elsevier: Amsterdam, The Netherlands, 2017; pp. 225-243.

27. Ramalakshmi, K.; Raghavan, B. Caffeine in coffee: Its removal. Why and how? Crit. Rev. Food Sci. Nutr. 1999, 39, 441-456. [CrossRef]

28. Srdjenovic, B.; Djordjevic-Milic, V.; Grujic, N.; Injac, R.; Lepojevic, Z. Simultaneous HPLC determination of caffeine, theobromine, and theophylline in food, drinks, and herbal products. J. Chromatogr. Sci. 2008, 46, 144-149. [CrossRef]

29. McCusker, R.R.; Goldberger, B.A.; Cone, E.J. Caffeine content of specialty coffees. J. Anal. Toxicol. 2003, 27, 520-522. [CrossRef] [PubMed]

30. Caprioli, G.; Cortese, M.; Sagratini, G.; Vittori, S. The influence of different types of preparation (espresso and brew) on coffee aroma and main bioactive constituents. Int. J. Food Sci. Nutr. 2015, 66, 505-513. [CrossRef]

31. Angeloni, G.; Guerrini, L.; Masella, P.; Bellumori, M.; Daluiso, S.; Parenti, A.; Innocenti, M. What kind of coffee do you drink? An investigation on effects of eight different extraction methods. Food Res. Int. 2019, 116, 1327-1335. [CrossRef]

32. Ravindran, R.; Jaiswal, S.; Abu-Ghannam, N.; Jaiswal, A.K. Two-step sequential pretreatment for the enhanced enzymatic hydrolysis of coffee spent waste. Bioresour. Technol. 2017, 239, 276-284. [CrossRef]

33. Vakalis, S.; Moustakas, K.; Benedetti, V.; Cordioli, E.; Patuzzi, F.; Loizidou, M.; Baratieri, M. The “COFFEE BIN" concept: Centralized collection and torrefaction of spent coffee grounds. Environ. Sci. Pollut. Res. 2019, 26, 35473-35481. [CrossRef]

34. Batista, L.R.; Chalfoun, S.M.; Silva, C.F.; Cirillo, M.; Varga, E.A.; Schwan, R.F. Ochratoxin A in coffee beans (Coffea arabica L.) processed by dry and wet methods. Food Control 2009, 20, 784-790. [CrossRef]

35. Dash, S.S.; Gummadi, S.N. Catabolic pathways and biotechnological applications of microbial caffeine degradation. Biotechnol. Lett. 2006, 28, 1993-2002. [CrossRef] [PubMed]

36. Jian, K.; Tong, W.; Hongyuan, Z.; Leilei, S. The extraction and mass transfer process of soluble solids in Russian olive. Afr. J. Plant Sci. 2013, 7, 407-413. [CrossRef]

37. Fick, A.V. On liquid diffusion. Lond. Edinb. Dublin Philos. Mag. J. Sci. 1855, 10, 30-39. [CrossRef]

38. Santana, Á.L.; Macedo, G.A. Effects of hydroalcoholic and enzyme-assisted extraction processes on the recovery of catechins and methylxanthines from crude and waste seeds of guarana (Paullinia cupana). Food Chem. 2019, 281, 222-230. [CrossRef] [PubMed]

39. Bustamante, P.; Navarro, J.; Romero, S.; Escalera, B. Thermodynamic origin of the solubility profile of drugs showing one or two maxima against the polarity of aqueous and nonaqueous mixtures: Niflumic acid and caffeine. J. Pharm. Sci. 2002, 91, 874-883. [CrossRef] [PubMed]

40. Zosel, K. Process for the Decaffeination of Coffee. U.S. Patent 42,606,39A, 7 April 1981.

41. Todd, R.; Baroutian, S. A techno-economic comparison of subcritical water, supercritical CO2 and organic solvent extraction of bioactives from grape marc. J. Clean. Prod. 2017, 158, 349-358. [CrossRef]

42. Shalmashi, A.; Golmohammad, F. Solubility of caffeine in water, ethyl acetate, ethanol, carbon tetrachloride, methanol, chloroform, dichloromethane, and acetone between 298 and 323 K. Lat. Am. Appl. Res. 2010, 40, 283.

43. Sondheimer, E.; Covitz, F.; Marquisee, M.J. Association of naturally occurring compounds, the chlorogenic acid-caffeine complex. Arch. Biochem. Biophys. 1961, 93, 63-71. [CrossRef]

44. Linares, A.R.; Hase, S.L.; Vergara, M.L.; Resnik, S.L. Modeling yerba mate aqueous extraction kinetics: Influence of temperature. J. Food Eng. 2010, 97, 471-477. [CrossRef]

45. Shalmashi, A.; Abedi, M.; Golmohammad, F.; Eikani, M.H. Isolation of caffeine from tea waste using subcritical water extraction. J. Food Process Eng. 2010, 33, 701-711. [CrossRef]

46. Deb, S.; Pou, K.J. A review of withering in the processing of black tea. J. Biosyst. Eng. 2016, 41, 365-372. [CrossRef]

47. Bi, W.; Zhou, J.; Row, K.H. Decaffeination of coffee bean waste by solid-liquid extraction. Korean J. Chem. Eng. 2011, 28, 221-224. [CrossRef] 
48. Gerke, I.B.B.; Hamerski, F.; de Paula Scheer, A.; da Silva, V.R. Solid-liquid extraction of bioactive compounds from yerba mate (Ilex paraguariensis) leaves: Experimental study, kinetics and modeling. J. Food Process Eng. 2018, 41, e12892. [CrossRef]

49. Hanson, C. Recent Advances in Liquid-Liquid Extraction; Elsevier: Amsterdam, The Netherlands, 2013.

50. Lide, D. CRC Handbook of Chemistry and Physics: A Ready Reference Book; CRC Press: Boca Raton, FL, USA, 2002.

51. Hildebrand, S. Standard Hildebrand values from Hansen. J. Paint Technol. 1967, 39, 505.

52. Fedors, R.; Van Krevelen, D.; Hoftyzer, P.; Barton, A.C. Handbook of Solubility Parameters and Other Cohesion Parameters; Barton, A.F.M., Ed.; CRC Press: Boca Raton, FL, USA, 1983.

53. Adjei, A.; Newburger, J.; Martin, A. Extended Hildebrand approach: Solubility of caffeine in dioxane-water mixtures. J. Pharm. Sci. 1980, 69, 659-661. [CrossRef]

54. Mohammed, M.J.; Al-Bayati, F.A. Isolation, identification and purification of caffeine from Coffea arabica L. and Camellia sinensis L.: A combination antibacterial study. Int. J. Green Pharm. IJGP 2009, 3. [CrossRef]

55. Ramón-Gonçalves, M.; Alcaraz, L.; Pérez-Ferreras, S.; León-González, M.E.; Rosales-Conrado, N.; López, F.A. Extraction of polyphenols and synthesis of new activated carbon from spent coffee grounds. Sci. Rep. 2019, 9, 1-11.

56. Bouhlal, F.; Aqil, Y.; Chamkhi, I.; Belmaghraoui, W.; Labjar, N.; Hajjaji, S.E.; Benabdellah, G.A.; Aurag, J.; Lotfi, E.M.; Mahi, M.E. GC-MS Analysis, Phenolic Compounds Quantification, Antioxidant, and Antibacterial Activities of the Hydro-alcoholic Extract of Spent Coffee Grounds. J. Biol. Act. Prod. Nat. 2020, 10, 325-337. [CrossRef]

57. Daglia, M.; Papetti, A.; Gregotti, C.; Bertè, F.; Gazzani, G. In vitro antioxidant and ex vivo protective activities of green and roasted coffee. J. Agric. Food Chem. 2000, 48, 1449-1454. [CrossRef]

58. Maegawa, Y.; Sugino, K.; Sakurai, H. Identification of free radical species derived from caffeic acid and related polyphenols. Free Radic. Res. 2007, 41, 110-119. [CrossRef]

59. Newton, D.W.; Kluza, R.B. pKa values of medicinal compounds in pharmacy practice. Drug Intell. Clin. Pharm. 1978, 12, 546-554. [CrossRef]

60. Martin, A.; Swarbrick, J.; Cammarata, A. Physical Pharmacy; Lea \& Febiger: Philadelphia, PA, USA, 1969.

61. Švorc, L.U. Determination of caffeine: A comprehensive review on electrochemical methods. Int. J. Electrochem. Sci. 2013, 8, 5755-5773.

62. Zuorro, A.; Lavecchia, R. Influence of extraction conditions on the recovery of phenolic antioxidants from spent coffee grounds. Am. J. Appl. Sci. 2013, 10, 478. [CrossRef] 